Canadian Journal of Fisheries and Aquatic Sciences

Canadian

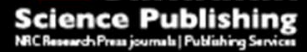

Journal canadien des sciences halieutiques et aquatiques

\title{
Eliminating implausible fisheries assessment models using fishers' knowledge
}

\begin{tabular}{|r|l|}
\hline Journal: & Canadian Journal of Fisheries and Aquatic Sciences \\
\hline Manuscript ID & cjfas-2017-0178.R1 \\
\hline Manuscript Type: & Article \\
\hline Date Submitted by the Author: & 31 -Jul-2017 \\
\hline $\begin{array}{r}\text { Complete List of Authors: } \\
\begin{array}{r}\text { Is the invited manuscript for } \\
\text { consideration in a Special } \\
\text { Issue? : }\end{array}\end{array}$ & $\begin{array}{l}\text { N/A lisea, Daniel; Ministère des Pêches et des Océans, Institut Maurice- } \\
\text { Kamontagne }\end{array}$ \\
\hline $\begin{array}{r}\text { Keyword: } \\
\hline\end{array}$ & $\begin{array}{l}\text { FISHERY RESOURCES < General, COMMERCIAL FISHERIES < General, } \\
\text { GROUNDFISH < Organisms }\end{array}$ \\
\hline
\end{tabular}




\section{Eliminating implausible fisheries assessment}

\section{2 models using fishers' knowledge}

3 Daniel Duplisea

4 Fisheries and Ocean Canada

5850 route de la mer

6 Mont-Joli, QC

$7 \quad$ G5H $3 Z 4$

8 tel: $418775-0881$

9 daniel.duplisea@dfo-mpo.gc.ca 


\section{1. Abstract}

11 Peer review of competing redfish (Sebastes mentella) assessment models revealed data inconsistencies where

12 stock biomass decline shown by the survey in the 1990s was too rapid to be explained solely by reported catch.

13 The models invoked different techniques to achieve fits, one by changing mortality at age and the other by

14 survey weighting. The former fitted reported catch well while the latter accepted a mismatch between reported

15 and estimated catch. The assessments produced different estimates of historical stock size and future

16 productivity. Interviews conducted with fishers of the stock suggested that catch was at least twice as high as the

17 official record. In light of the fishers' evidence, the model that invoked a large change in mortality with age in

18 order to follow reported catch closely now appears less credible. This serves as a warning against introducing

19 new biological mechanisms without credible justification. This is an example of how indicators derived from

20 fisher's knowledge, even if only from a small number of interviews, can be used to eliminate less plausible

21 models.

22

\section{2. Keywords}

24 fisher knowledge, traditional ecological knowledge, benchmark, framework, peer review, Laurentian Channel,

25 Gulf of St Lawrence, Scorpaenidae 


\section{3. Introduction}

27 How to incorporate fisher knowledge (FK) into quantitative stock assessment is not always clear. FK information

28 is often qualitative and may be perceived to be incompatible or even counterpoint to standard science data

29 (Agrawal 1995). FK may be considered biased by experts and not robust relative to scientific data and

30 assessment. Experts are potentially consciously or unconsciously prejudiced towards holders of FK (Soto 2006).

31 There are numerous reasons why FK may not often be used in assessment (Agrawal 1995; Soto 2006) but it is

32 widely acknowledged that bringing FK into stock assessment and developing a joint research and assessment

33 plan is essential for good long term fishery management (Neis et al. 1999; Johannes et al. 2000; Mackinson 200;

34 Stephenson et al. 2016). There are many benefits to this including better results but also more effective

35 implementation of scientific advice since the process of developing and executing the joint research and

36 assessment program leads to increased trust between the users, scientists and managers (Holm 2016). Studies

37 have shown the FK is trustable and confirms scientific measurements of fish community structure (Hallwass et

38 al. 2013). FK can be used to fill gaps in scientific information (Bevilacqua et al. 2016) address the problem of the

39 shifting baseline especially when scientific survey data do not extend back very far but knowledge of appropriate

40 historical baselines can be found in the collective knowledge of fishers (Sáenz-Arroyo et al. 2005). Hypothesis

41 have been tested to examine the nature of the fisher response group and potential samplings biases (Lima et al.

42 2016). Clearly, there is an established base showing the value of using FK in fisheries assessment and

43 deepening joint research assessment programs in fisheries should be a priority; however, it may be sometime

44 before the benefit of this is felt in fisheries that have only recently embarked on this way of working. There exists

45 however, another possibility for effectively using FK in stock assessment even if collection of FK only recently

46 began. This is by using FK as a data source to test hypotheses (Silvano and Valbo-Jørgensen 2008) when faced

47 with a suite of competing hypotheses. Competing assessment models are validly viewed as competing

48 hypothesis for stock dynamics. Testing models with FK is done by testing model inferences, e.g. estimates of

49 say historic catch, against FK derived data about catch. The advantage of this is that FK is used as a tool to

50 eliminate hypothesis which requires less evidence than the much more ambitious goal of putting forward a hard

51 inductive approach which demands FK data of similar characteristics to scientific data such as a trawl survey

52 index. Using this Popperian empirical falsification approach (Corkett 2002), the burden of proof for data use in 
53 assessment modelling shifts to showing that the models are consistent with the FK data, not that the FK data are

54 usable in the model. For instance, in a situation where competing assessment models are fitted using the same

55 data, and model diagnostics do not lead to a clearly better model, FK could be the empirical basis to falsify one

56 or more of the approaches if we consider models as hypotheses.

57 Fisheries assessment modelling is a standard tool in regions where scientific data and expertise in fisheries and 58 statistics and collection of long running scientific data sets have a strong tradition such as the Canada, USA and Western Europe. These models require a considerable amount of scientifically collected data such as survey

60 indices of abundance at age, detailed commercial catch sampling at age, knowledge of maturity, mortality and

61 size at age as well as assumptions about the efficiency of the fishing fleets for catching different ages of fish.

62 They are resource demanding and expensive tools for providing fishery advice but they have advantages. Some

63 of the most useful aspects of having an assessment model for a population or stock is that historical estimates of

64 stock size and production can be estimated, sustainable harvest strategies can be developed around

65 productivity based reference points and mainly, models allow prediction into the future. Most stock assessments

66 in Canada strive to have an analytical model which fits the data well and holds up in peer review. That said, most

67 stocks in Canada are not assessed using a model of this sort and science advice to fishery managers is based

68 on a survey index and in some cases no assessment is done at all but the fishery is controlled through

69

70 measures associated with licencing. When a model does form the basis of the scientific assessment, it becomes necessary to peer review it and subject it to a variety of tests since the science advice derived from these models can have important implications for people's livelihoods and local economies.

Unit 1+2 redfish (Sebastes spp.) off eastern Canada (Fig 1) was the focus of the current study where two modelling approaches were put forward for assessment in a peer reviewed "Framework" meeting in December 2015 (DFO 2016). The peer review meeting on these approaches was unable to select one model over the other as the best way forward for assessment of this stock since some diagnostics were not informative and it was difficult to compare between models. This is not an uncommon situation for statistical catch at age/length models which are often highly complex with many different levers, some of which are used or not simply on the basis of the assessor expert knowledge or intuition. Decisions such as data weighting, selectivity curves, recruitment model, mortality at age, weight at age can sometimes be chosen this way though statistical techniques to do this more objectively is an active area of fisheries modelling research (Butterworth and Rademeyer 2008; Francis 
81 2011; Maunder et al. 2017). Because the models are complex, it can be difficult to present them fully or even 82 appreciate their strengths and weaknesses in a 2-3 day peer review process. Considerable trust is placed in the 83 main model assessors at these meetings to show not only strengths but also weaknesses of their approaches to 84 develop a sufficient suite of diagnostic checks to allow adequate model evaluation. The subjectivity of words 85 such as "sufficient" and "adequate" in the previous sentence exposes that the peer review process has an 86 important ethical and trust-based component. In this mileau of biology, statistics, information, knowledge, trust 87 and ethics there is an important place for model inference hypothesis tests. Data derived from FK may be an 88 effective method of reducing model uncertainty in a competing model process through hypothesis testing and 89 model elimination.

90 The peer review framework in December 2015 failed to eliminate one of the models and thus could not settle on 91 an assessment method. Both models had difficulty reconciling stock declines with reported catch, but the two 92 approaches took diametrically opposite means to address it. One model followed the Francis (2011) guiding 93 principle of fitting the main stock index well but estimated catch in the 1990s that was much larger than reported.

94 The other model introduced a change in natural mortality at age which explained the rapid stock decline while 95 also following reported catch closely; however, the mortality at age function did not conform with established 96 ideas of how mortality changes with size and age in fish (Kenchington 2014). If one model were chosen over the 97 other it would have had important implications for estimates of historical stock size, reference points and most 98 importantly projections for future catch and harvest advice.

\section{4. Methods}

\section{4.1 Species and study area}

101 Redfish (Sebastes spp.) in eastern Canada is dominated by two species: the Acadian redfish (S. fasciatus) and 102 deepwater redfish (S. mentella). These are long lived species and individuals $>65$ years old are not uncommon

103 (Campana et al. 1990). They grow slowly, have a low natural mortality rate, old age at maturity (about 8) and do 104 not begin to recruit to the fishery until about age 7 and $22 \mathrm{~cm}$ (Duplisea et al. 2016). They are characterized by 
105 highly variable recruitment dynamics with occasional large year classes and 10-30 years of very low recruitment 106 during interim years (Valentin et al. 2015).

107 The Unit 1+2 stock area of redfish is concentrated along the Laurentian Channel in eastern Canada (Fig. 1). The 108 area is considered to have two redfish stocks: one for each of the two species. The management areas of Unit 1 109 and Unit 2 are treated separately. Unit 1 has been the traditional area of large S. mentella populations and 110 fisheries but since the large reductions in permitted catch after 1994, Unit 2 has been the area of more fishing 111 activity. Canadian Department of Fisheries and Oceans (DFO) scientists provide advice to managers for these 112 stocks on a two year basis but between 2011 and 2017 there were more frequent status updates, e.g. (DFO 1132016 b; 2017) primarily owing to abundant year classes in 2011-2013.

\section{$114 \quad 4.2$ Peer review and modelling approaches}

\section{4.2.1 Peer review}

116 The peer review approach for selecting an assessment model in DFO is termed an assessment framework 117 review. An assessment framework review is usually required to settle on an approach which could be used as the basis of the stock assessment over one or more assessment cycles. These meetings are usually about two days but there is no restriction on their length, the goal being simply that there has been a peer review sufficient so that a model can form the defensible basis for an assessment. Peer review participants usually consist mostly of DFO scientists with 1-3 external reviewers from outside of DFO, one of whom is often international. Only in recent years has the fishing industry taken an interest in attending framework meetings and industry is permitted to table an assessment with sufficient notice. Terms of Reference for framework meetings are produced well in advance, and can be quite specific (see Appendix A for TOR for the December 2015 meeting). It is understood that a framework meeting's goal is to come out with an acceptable model for the stock assessment. An accepted model is considered final but minor changes, data updates, points of clarification are allowed to models accepted

127 at peer reviews but large changes are not permitted and the next assessment's results often are obvious by the end of the framework meeting when a model is agreed upon. 


\subsubsection{Modelling approaches}

130 Redfish are difficult to age with standard methods therefore age-based modelling approaches cannot always be 131 applied; nevertheless, a considerable amount of survey and catch length composition data are available for the 132 Unit 1+2 stock. In order to utilise as much available data as possible, length-based age structured modelling e.g. 133 (Fournier et al. 1998) was seen as promising. Two statistical catch at length models were put forward as 134 assessment approaches for these stocks:

135 Model 1: is a relatively simple statistical catch at length model developed by the National Oceanic and 136 Atmospheric Administration (NOAA) in the United States and is freely available for download as part of the 137 NOAA Fisheries Toolbox (nft.nefsc.noaa.gov) as the model "SCALE". SCALE forces certain parsimonious 138 assumptions such as a logistic selectivity curve for the fishery, temporally constant growth and a single $\mathrm{M}$ over all ages which was input as 0.1 (Fig. 2). The main survey index was right-weighted (sensu Francis 2017) by a factor of 7 in the likelihood function for the model fitting reported here. SCALE's graphical front end generates a standard input file and outputs can be read by the program and plotted or imported into other software. The modelling approach has been applied for various stocks on the Northeast USA shelf e.g. (NOAA 2007) while

143 (Duplisea et al. 2016) outline the specific assumptions and fittings of this approach for Unit 1+2 redfish.

144 Model 2: is more complex than Model 1 and incorporates Bayesian priors on several parameters. It also has a 145 more flexible selectivity curve structure which can be dome shaped or multimodal, though key run parameters were constrained to be logistic. This model also allowed a variable mortality at age and was considered to be 0.4

147 for ages 0 to 13 and 0.05 for older ages (Fig. 2). Model 2 also down-weighted (sensu Francis 2017) the first five 148 years of the main survey index by a factor of 20 in the likelihood function owing to a vessel change in 1990 149 (though the survey was corrected through comparative tow experiments). A detailed explanation of model 150 structure, assumption and fitting is found in Rademeyer and Butterworth (2015). All data for Model 2 except for 151 total catch were read from (electronically digitised from image files) from the figures in (Rademeyer and 152 Butterworth 2015).

153 These modelling approaches required similar inputs, i.e. survey indices and composition data in length, growth 154 rate and by making assumptions about variation in growth these models essentially fit numbers at age. Perhaps 155 the key difference between the two approaches was the natural mortality at age assumption. Model 1 used a 
156 constant mortality over all ages of 0.1 while Model 2 used a stepped mortality at age function ( 0.4 from ages 1 to

15713 and 0.05 thereafter. Model 2 also incorporated soft constraints as penalties for deviations from reported catch

158 and survey catchability coefficients outside the range 0.1 and 2 . The likelihood functions of the models were also 159 constructed somewhat differently where Model 1 fitted survey adult abundance while Model 2 survey fitted total 160 biomass. This means that the presentation of outputs is sometimes not directly comparable on the same graph 161 but still conceptually similar.

\subsection{Changes in the fishery 1986-1994}

163 164 165 166 167 168

In the late 1980 s and early 1990s groundfish fisheries in eastern Canada were changing rapidly and fishing effort aimed at cod (Gadus morhua) was being redirected to other species including redfish (Sebastes spp.) (Goetting 2008). Representatives of the fishing industry also report a large effort of $25 \mathrm{~m}$ vessels operating year round in redfish areas (e.g. Jason Spingle, Food Fisheries and Allied Workers, St John's NL, Canada. Pers Comm) and the possibility of discarding, high grading and other practices which may have led to higher than reported catch rates for several species. At the same time, the redfish fishery itself was re-gearing towards midwater trawls and steel-hulled vessels enabling a year-round fishery. Midwater trawls can also subject juvenile redfish to a greater fishing mortality rate than bottom trawling as juveniles are more pelagic than adults. Because of the changes noted in the fishery in this period, it is reasonable to hypothesize that reported catches of redfish in the late 1980s and early 1990s may be an underestimate of actual catches in this period and may not properly represent the size composition of catches. If there is support for this hypothesis, it lends credence to supporting a model that estimates catches which were larger than reported in this period to explain the rapid decline in stock biomass rather than a model that introduces new biological mechanisms (changes in mortality at age) to explain the decline.

Because of the changes in the fishery during this period and the possibility that fishing practices and catch reporting may have been affected by those changes, it was decided to conduct interviews with fishers who were active during this transition period to gain first person evidence of the nature of the fishery then. 


\section{$180 \quad$ 4.4 Surveys of fishers}

181 Industry participants who were active during this period were interviewed by telephone in January-February

182 2016. We found initial industry participants through a letter to the editor of a eastern Canadian fishing industry

183 magazine, The Navigator, asking for anyone involved in redfish fisheries at this time to get in contact. This led to 184 other contacts. In addition, present day fishing industry participants were asked for contacts of fishermen in this 185 period in a process called snowball sampling (Neis et al. 1999). This led to a total of 10 interviews which covered 186 most of the major redfish fishing and processing ports in the region for that period (Figure 1).

\section{$187 \quad$ 4.4.1 Interviews}

Interviews were conducted in an open format where core questions were asked during each interview but

189
interviewees were welcome at any time to discuss other topics or elaborate on their ideas. The core questions formed the bulk of the main results here but the open interview format did provide useful information on gear, behavioural shifts owing to sea ice conditions, times of day fished, gear bottom type interactionsand processing

192 that would not have come simply from direct answers to the core questions (Neis et al. 1999).

\section{Core questions:}

- How big was the vessel you fished?

- What was the hold capacity of your vessel?

196 - What gear type did you use?

- Was all the catch landed?

- Where did you fish?

- Where did you land most of your catch?

- Did you fish all year long or for how much time during a year?

201 - In which years were you active in the fishery? 
- Was the catch composition different between periods?

- Could you roughly estimate the proportion of your catch which was large fish vs small fish?

- What would you consider to be size demarcating small vs large fish?

- Did you discard fish and if so why and how often?

- Were there differential prices for your catch based on size composition?

- What happened to the fish once it was taken in at a plant?

Not all questions applied to all those interviewed as some industry participants worked only in processing plants, others only at sea, while one other ran shore-based operations involving the redfish fleet. This diversity of participants provided several insights which would not have been available if only type of industry participant was interviewed. A common characteristic of all but one interviewee was that they had left the fishing industry and were into retirement age ( $>60$ years old).

The responses to these questions usually allowed the calculation of annual catch by boat, port or region (Duplisea et al. 2016). In the case of a large vessel operating out of one port, a skipper reported the vessel's capacity, that the vessel always came back to port full, that the vessel made on average a certain number of trips per year and the time periods when this occurred, and from where the fish were caught. This allowed the calculation of annual catch for that vessel. A fisher might also report the number of vessels of this size fishing in the same manner out of their home port, in which case a port catch could be calculated. In other cases similar vessels from other ports were fishing the same aggregations of fish and with this information an approximate aggregate catch could be calculated. In this way, fisher knowledge catch estimates (FKCE) for different periods could be determined. The FKCE can be considered a quasi-quantitative indicator of catch since it indicates the rough magnitude of catch but should not be considered a means to correct official catch statistics nor as an absolute level of catch that could be added to other reported catches. Several assumptions about vessel distribution and manner of fishing as well as season were necessary to extrapolate from interview catch estimates to a collective FKCE. The FKCE is nevertheless a useful piece of information which, like any other kind of information, can be a powerful if used in the correct context. 
228 The redfish fishery was concentrated in a few ports and processing in even fewer, while there were not huge 229 numbers of individual boats (less than one hundred boats in this period); therefore, there is some confidence 230 that FKCE might approach actual catches. Also, because none of the fishing activities were forbidden at the time 231 and most fishers and boats are no longer fishing, the results can viewed as unbiased. FKCE may be considered 232 an estimate of minimum catch because some ports were not sampled and foreign catches were not included.

\section{5. Results}

\section{$234 \quad 5.1$ Model fits to main survey index}

Model 1 followed the main survey (Unit 1) adult index well (Fig 3). One of the features of this time was the declining abundance of adults from year classes in the early 1970s with an increasing abundance in the adult index of the of the early 1980 year class (Fig 3a), which is captured by the model. In contrast, Model 2 tends to under-estimate the biomass in the 1980s and shows a decrease in biomass through the period of collapse from 1995 until 2012 (Fig 3b). Model 1 predicted higher catches in a few years for the period of collapse during the 2000s.

\subsection{Model fits to survey composition}

Both models had difficulties fitting the length $19-40 \mathrm{~cm}$ length composition of the main survey index (Fig 4). In the earlier part of the series (the pre-collapse period 1984-1991), Model 1 (Fig 4) captured the composition better than Model 2 (Fig 4). In the collapsing through collapsed period, Model 1 tended to overestimate the abundance of smaller fish and under estimate the proportion of larger fish. Model 2 fitted data in the collapse period better than Model 1 but tended to underestimate the proportion of medium sized fish.

\subsection{Model fits to reported catch}

Catch for model 1 was followed quite closely except in the late 1980 and early 1990s when it predicted a much higher than reported catch (Fig 5a). This catch residual was about double the reported catch in 1990/91 (Fig 5b). Other model runs which were not implausible showed catch residuals as much as 3-4 times the reported catch in 
251 this period. Model 2, however, followed the reported catch almost perfectly except for a small deviation in the 252 mid 1960s (Fig 5b). Model 1 also suggest higher than reported catch for some points in the mid 2000s.

\section{$253 \quad 5.4$ Total biomass estimates}

254 Estimates of total biomass from Model 1 peaked at about $700 \mathrm{kt}$ in 1968, declining to about half that biomass 255 soon after until the early 1990s where the stock quickly collapsed to a very low biomass (Fig 6). Model 1 showed 256 a recent large increase in total biomass as a result of the appearance of the large 2011-2013 cohorts. Model 2 257 estimated a considerably larger total biomass than Model 1. Model 2 estimated peak biomass to almost $1900 \mathrm{kt}$ 258 in 1986 with a rapid decline to the mid-1990s to just over $15 \%$ of that peak. Model 2 also estimated the large increase in biomass due to recent cohorts. No estimates of biomass were provided for Model 2 prior to 1980 so it is not certain what the biomass estimates in the 1960s would have been, but it is likely that these biomass estimates would be much larger than the $1900 \mathrm{kt}$ peak in 1986. This is because model scaling is largely driven by reported catch and between 1960 and 1980 reported catch was much larger than the 1980s catch (Fig 6). For the common period estimated by both models (1980 onward), there are similarities in dynamics but large differences in scaling.

\subsection{Reference points and stock productivity}

There is no clear way to derive productivity based reference points for this stock from these models since recruitment was estimated freely and was highly variable with little evidence of a stock-recruitment relationship. In cases like this, biomass reference points may be derived from proxies based on inflections or periods of relative stability in catch and biomass. For the sake of consistency between the two models, a biomass target which may have some bearing on the biomass giving the maximum sustainable yield is the mean biomass in the period from 1980-1990. For Model 1, this is about $300 \mathrm{kt}$ and $1500 \mathrm{kt}$ for Model 2 (Figure 6). This would suggest that Model 2 scaled biomass by about a factor of 5 compared to Model 1. Regardless of the specific method used for that scaling, such as a stable period or the whole time series (factor of 3.2), there is a many fold difference in scaling between the two models which has direct implications for biomass and fishing mortality reference points and fishery advice. Model 1 would suggest a longer term fishing strategy since individuals would be expected to remain in the population for many years if not fished. Model 2 would suggest a fishing 
277

278

279

280

strategy that should target redfish as young as possible and high catches early in life before fish die from the high level of natural mortality assumed in that model.

\subsection{Fishers' impressions of catch}

The survey of fishers who fished in the 1980s and 1990s on this stock revealed a much larger than reported catch in the late 1980s and early 1990s (Fig 7). Fishers reported landing many more small fish than in the official catch record. Most of these small fish went into the production of fish meal and or bait and apparently were were not reported as catch. The FKCE minimum catch estimates in 1990 and 1991 were about double the reported catch in that period.

The proportion of small fish $(<20 \mathrm{~cm})$ reported in the DFO catch is low and peaks at only $2.7 \%$ of the total reported catch weight in 1991. This contrasts with what some fishers reported where small fish constituted 20$50 \%$ of catch weight in the late 1980 s and early 1990 s. These fishers reported some discarding practices but not a large amount, primarily because the quotas were not restrictive and there was little incentive for high grading in the early period. Some of the most important fishing grounds were only a short steam from the landing ports and it was more efficient for catch to be sorted upon processing than at sea but this likely varied with price and distance between port and fishing areas. Several interviewees reported that in the early 1990s a small small-fish market was developed by some of the processors with differential pricing. This created both a use for smaller fish and also an incentive to high grade to larger fish which had a higher price. Roughly converting these small fish catch proportions in biomass to abundance could have meant that about $50-80 \%$ of the numbers of fish caught were small fish.

\subsection{Eliminating the less plausible model}

The FKCE suggests that catch was much higher than what was recorded in the official catch record and that many more small fish were also killed in fishing operations than shown in the catch record. Model 2 followed the catch record data very closely while Model 1 suggested that catch in the early 1990s was about twice that of the official record (Fig 5). Model 1 also followed the decline in the abundance of the early 1970s cohorts in the mid 1980s with an increasing abundance of the $1980 / 81$ cohort, after which there is an important stock structure 
302 feature (Fig 3) that helps the model estimate stock productivity. Comparing model predictions against FKCE 303 suggests that, although Model 2 followed the official catch record closely, it underestimated actual catch.

304 Conversely, Model 1 estimated that actual catch must have been larger than reported in the early 1990s and 305 followed an important feature of the main survey index better than Model 2 in the mid 1980s.

306 6. Discussion

307 The present study shows how fisher knowledge can be used to eliminate less plausible models in a competing 308 model process. Without introducing extra mechanisms or weights, both modelling approaches had difficulty

309 reconciling the speed of biomass decline in the early 1990s. Model 1 attempted reconciliation by accepting catch residuals in that period while ensuring that the survey index broad features were captured thus suggesting that catch was higher than reported. Model 2 attempted reconciliation by introducing a split in the main survey index weighting in 1990 and introduced a varying mortality at age mechanism whereby a high mortality rate (0.4) was experienced by the first 13 age classes then declined eight-fold for ages 14 and older. Model 2 was able to follow reported catch closely while also showing the decline in the 1981 year class to low levels 13 years later in 1994. The low mortality rate (0.05) in Model 2 from age 14 onward combined with the great longevity of redfish meant that the remaining modelled population persisted at very low levels for many years after 1994. Model 2, therefore, followed the data closely but only by introducing a biologically unrealistic mortality function (see below for reasons why this mortality function is not realistic) and differentially weighting the main survey index over time, neither of which were well justified. Model 1 clearly did not follow all the data well and accepted the estimated catch was much larger than the input catch data in the 1990s. Model 1, however, followed the main survey index well (Francis 2011) particularly in the dynamic period of the 1980s and did not require the introduction differential weighting in time of the survey index or new biological mechanisms. The subsequent analysis of reported catch compared to FKCE showed that Model 1 was the less implausible of the two approaches since fishermen themselves suggest they caught more fish and many smaller fish than what were present in the official catch statistics (Duplisea 2016; Duplisea et al. 2016).

Obtaining useful estimates or inputs of natural mortality (M) of fish populations is one of the most important and difficult to inform uncertainties in fisheries assessment models (Brodziak et al. 2011). M is often kept constant at a "sensible" value in fisheries models because it is better to leave alone this parameter if one does not know how 
329 justifiably vary it since it is completely confounded with fishing mortality estimated by the model. Despite the 330 difficulty prescribing what $\mathrm{M}$ should be in fisheries models, it is much easier to say what $\mathrm{M}$ should not be. Many 331 rules of thumb exist for estimating $\mathrm{M}$ (Kenchington 2014). For example, it is a truism that a fish population with 332 old average maximum age must not have an $\mathrm{M}$ so high as to prevent an appreciable number of individuals from 333 reaching that age (Hoenig 1983). It is also well known that mortality of marine fish is largely a function of body

size (Lorenzen 1996) and that size is primarily a function of age in marine fish. That is, small/young fish experience greater natural mortality than old ones due to predation, density dependence and increased vulnerability to environmental influences (Sogard 1997). Age 13 and 14 redfish in this stock area are fully mature and the average size of an age 13 redfish is about $30 \mathrm{~cm}$ and an age 14 redfish about $31 \mathrm{~cm}$ with growth rate $<1$ $\mathrm{cm} /$ year at these ages. Redfish in the $>30 \mathrm{~cm}$ are much larger than the sizes when they are likely to experience high predation and their natural mortality rate is conceivably larger. Therefore, it is difficult to find an ecological mechanism which inflicts so much more mortality on a $30 \mathrm{~cm}$ redfish than a $31 \mathrm{~cm}$ redfish. The large change in natural mortality from age 13 to 14 in Model 2 apparently has little ecological justification. The ability of Model 2 to fit the catch data well comes at the expense of biological realism, and the implications for projections and fisheries advice are considerably different and much more conservation risk prone than Model 1.

Most research shows that plausible models of natural mortality for fisheries assessment include constant $\mathrm{M}$ at age/length or a smoothly varying non-linear approach with high $\mathrm{M}$ at small size decreasing to the largest size (Gislason et al. 2010; Kenchington 2014). A Model 2 alternative fitting explored a linear declining M from age 5 to age 14 of 0.40 to 0.05 while keeping the time difference in survey index weighting (Rademeyer and Butterworth 2015). This alternative fitting produced much lower estimates of biomass and year class strength which were closer to that of Model 1, although catch estimates were not reported for this $\mathrm{M}$ sensitivity run. Although not amongst the preferred methods for modelling $\mathrm{M}$ at age (a non-linear decline over all ages has greater ecological justification), this was an improvement over the Model 2 base fitting and it suggests that greater biological realism in the way M is modelled may be a way to reconcile Model 1 and Model 2 .

This exercise in selecting models for assessment is not purely academic. There are real implications for fisheries advice going forward which depend on model selection and these choices can directly affect people's livelihoods. Model 1 essentially predicts a long lived stock which can support moderate fisheries when large and almost randomly occurring year classes recruit. Because Model 1 has a relatively low natural mortality (0.1), a 
357 fishery can exploit a single year class for many years without it being too heavily depleted by natural mortality 358 and thus would favour a longer term exploitation strategy with a gradual increase and then decrease in fishing

359 360 361 362 363 364 365 366 367 368 369 370 capacity as the cohort recruits and is fished out. Model 2, on the other hand, predicts similar almost randomly occurring strong year classes but because natural mortality is so high on the first 13 ages (0.4) the management advice would be to fish very hard as soon as possible to maximize yield before natural mortality kills off all the fish. Fishery advice consistent with Model 2 therefore would be more prone to creating high conservation risk especially if there turns out to be a clearer stock-recruitment relationship than revealed by current data, i.e. it could lead to recruitment overfishing. Model 1 fishery advice would be less conservation risk prone because it would not recommend as much fishing as quickly and would give more reproductive opportunities to mature fish. In addition, Model 1 accords better with the smoother and more gradual building and dismantling of fishing capacity and economics preferred by fishing fleets. Model 2 clearly has more inherent conservation risks than Model 1and subjecting and single assessment model to the litmus test of fisher knowledge would be important going forward to avoid generating advice that could prove deleterious to the stock and fishery (Johannes et al. 2000).

The method of using stakeholder knowledge to essentially rank model plausibility then eliminate the less plausible ones requires that assessment models are thought of as hypotheses of how the fishery system works. In this way, it is more easily seen how less plausible models can be eliminated from suite of models. This is useful because the burden of proof for hypothesis elimination is less than that for putting forward ideas requiring support. Much of the information which can be gathered from fishermen and other stakeholders may not be rigorously quantitative or systematic and is spatially limited (Neis et al. 1999) but the reduction in burden of proof for hypothesis elimination means that this kind of information can still be useful in a model selection/elimination framework. This kind of knowledge is however less useful if only one hypothesis is presented. That is, if there is only one proposed model and one must have a model to move forward then the burden of proof is higher. This is particularly true if the implications of not selecting an approach/hypothesis are potentially harmful. This is another means of stating the precautionary principle (Garcia 1994) in a models-as-hypotheses fisheries context. Therefore, it must be recognised that hypothesis elimination with stakeholder information (or any other information) does not equally apply in all contexts. It is most useful in a multiple model/hypothesis context but less useful in a single model context where burden of proof for hypothesis rejection must be balanced with the 
385 reversal of burden of proof implicit in the precautionary principle. In some cases it may be necessary to accept, 386 for operational purposes, a model/hypothesis which has issues and objections because the implications of not 387 doing so would lead to inaction and violate the precautionary principle. Such a judgement is not, however, solely 388 at the discretion of scientists.

389 This study present how models are sometimes set to compete against each other in a peer review which has the 390 goal of selecting only one of the models. This approach is, however, not considered to be the ideal framework for fisheries assessment and management with the development of management strategy evaluation (MSE) also known as management procedures (Butterworth 2007, Punt et al. 2014). MSE seeks to overcome many of the issues of competing model approaches by elevating the question from "what is the best model ?" to "what is the management procedure for the stock that is mostly likely to achieve the stakeholder objectives ?". MSE, is a notable addition to traditional approaches but there are critics (Rochet and Rice 2009) and it comes with costs including monetary as well as considerable background trust building work between stakeholders that can take many years (Butterworth 2007). MSE is potentially a brittle framework that requires all participants behave according to a set of ground rules and deviations from those rules undermines the process. For these reasons, it is not enough simply to state the desire to elevate difficult problems in assessment model selection to an MSE process when there may be avenues remaining for elimination of less plausible candidates. In some cases, MSE may be a clear and productive way forward but, there is a demanding level of resources and commitment which must accompany the desire to go the MSE route. A competing model approach is therefore likely to remain an important way of peer-reviewing and selecting assessment models when MSE conditions and commitments are not sufficiently met.

405 The approach of using stakeholder knowledge, be it considered quasi-quantitative or even qualitative, has 406 proven to be useful to eliminate an apparently plausible model. These models were considered plausible 407 because they were proposed and defended in a peer review process as credible assessment approaches by 408 their advocates (Rademeyer and Butterworth 2015; Duplisea et al. 2016). Model 2 introduced a biologically 409 difficult model to justify mortality function that enabled the model to estimate reported catch data almost 410 perfectly. It is only in light of subsequent information gleaned from interviews with fishers that Model 2 was able 411 to fit a catch series with serious issues and Model 2 is now seen as problematic because it introduced an 412 implausible biological mechanism to explain erroneous data. This serves as a warning about the introduction of 
413 new mechanisms in fisheries assessment models to better explain data without first exploring the quality of 414 inputs in greater depth, especially if there is reason to suspect the veracity of some of the inputs. Also, the up415 weighting or right-weighting of data which are considered good and which are the most important to follow, e.g. 416 (Francis 2017), should be considered a more prudent strategy to achieve model fits than introducing new 417 mechanisms that are not well founded. More importantly, this series of interviews with fishermen and the FKCE 418 derived from them provided evidence which can be used to eliminate less plausible hypotheses (models) in a 419 competing hypothesis framework. This can be a more productive way to incorporate stakeholder knowledge in 420 the assessment process than insisting on stakeholder inputs on the same level of rigour as other assessment 421 model inputs while FK can have much broader uses in fisheries assessment especially if there is a well422 established means of collecting it and a time series can be developed.

\section{7. Acknowledgements}

424 A DFO redfish stock assessment requires contributions from many people such as port samplers, survey crew, 425 database experts, redfish biologists, geneticists, statisticians and industry all of whom deserve credit here.

426 Thanks are of course due to the fishers who openly shared their knowledge with me. Paul Nitschke from NOAA 427 Woods Hole helped considerably with SCALE. Comments by two anonymous reviews greatly improved the 428 manuscript. 


\section{References}

431

432

433

434

435

436

437

438

439

440

441

442

443

444

445

446

447

448

449

450

451

452

453

454

455

456

457

458

459

460

461

462

463

464

465

Agrawal, A. 1995. Dismantling the Divide Between Indigenous and Scientific Knowledge. Dev. Change 26(3): 413-439. Blackwell Publishing Ltd. doi:10.1111/j.1467-7660.1995.tb00560.x.

Bevilacqua, A.H. V, Carvalho, A.R., Angelini, R., and Christensen, V. 2016. More than anecdotes: fishers' ecological knowledge can fill gaps for ecosystem modeling. PLoS One 11(5): e0155655. Public Library of Science.

Brodziak, J., lanelli, J., Lorenzen, K., and Methot, R.D. 2011. Estimating Natural Mortality in Stock Assessment Applications. NOAA Tech. Memo. NMFS-F/SPO.

Butterworth, D.S. 2007. Why a management procedure approach? Some positives and negatives. ICES J. Mar. Sci. 64: 613-617.

Butterworth, D.S., and Rademeyer, R.A. 2008. Statistical catch-at-age analysis vs. ADAPT-VPA: the case of Gulf of Maine cod. ICES J. Mar. Sci. J. du Cons. 65(9): 1717-1732.

Campana, S.E., Zwanenburg, K.C.T., and Smith, J.N. 1990. 210Pb/226Ra Determination of Longevity in Redfish. Can. J. Fish. Aquat. Sci. 47(1): 163-165. NRC Research Press. doi:10.1139/f90-017.

Corkett, C.J. 2002. Fish stock assessment as a non-falsifiable science: replacing an inductive and instrumental view with a critical rational one. Fish. Res. 56(2): 117-123. doi:http://dx.doi.org/10.1016/S01657836(01)00352-6.

DFO. 2016a. Proceedings of the Zonal Peer Review of the Assessment Framework for Units 1+2 Deepwater (Sebastes mentella) and Acadian Redfish (Sebastes fasciatus) and for Unit 3 Acadian Redfish. Can. Sci. Advis. Secr. - Proc. 2016/038.

DFO. 2016b. Assessment of redfish stocks (Sebastes fasciatus and S. mentella) in Units 1 and 2 in 2015. Can. Sci. Advis. Secr. - Sci. Advis. Rep. 2016/047.

DFO. 2017. Update of main indicators of stock status for Unit 1 and 2 redfish in 2016. Can. Sci. Advis. Secr. Sci. Advis. Rep. $2017 / 023$.

Duplisea, D.. 2016. Context and reinterpretation of reported redfish catch in Unit 1+2 in the 1980s and 1990s based on interviews with industry participants. Can. Sci. Advis. Secr. - Res. Doc. 2016/103.

Duplisea, D.E., Bourdages, H., Brassard, C., Gauthier, J., Lambert, Y., Nitschke, P.C., and Valentin, A. 2016. Fitting a statistical catch at length model (NFT-SCALE) to Unit $1+2$ redfish (Sebastes mentella \& Sebastes fasciatus). Can. Sci. Advis. Secr. - Res. Doc. 2016/095: 36 pp. Ottawa.

Fournier, D.A., Hampton, J., and Sibert, J.R. 1998. MULTIFAN-CL: a length-based, age-structured model for fisheries stock assessment, with application to South Pacific albacore, Thunnus alalunga. Can. J. Fish. Aquat. Sci. 55(9): 2105-2116. NRC Research Press.

Francis, R.I.C.C. 2011. Data weighting in statistical fisheries stock assessment models. Can. J. Fish. Aquat. Sci. 68(6): 1124-1138.

Francis, R.I.C.C. 2017. Revisiting data weighting in fisheries stock assessment models. Fish. Res. 192: 5-15. Elsevier. 
466 Garcia, S.M. 1994. The precautionary principle: its implications in capture fisheries management. Ocean Coast.

467

468

469

470

471

472

473

474

475

476

477

478

479

480

481

482

483

484

485

486

487

488

489

490

491

492

493

494

495

496

497

498

499

500

501

502 Manag. 22(2): 99-125.

Gislason, H., Daan, N., Rice, J.C., and Pope, J.G. 2010. Size, growth, temperature and the natural mortality of marine fish. Fish Fish. 11(2): 149-158.

Goetting, K. 2008. Is fisheries diversification a sustainable strategy? The case of the Newfoundland redfish fishery. MSc Thesis. Meml. Univ. Newfoundl.: 65.

Hallwass, G., Lopes, P.F., Juras, A.A., and Silvano, R.A.M. 2013. Fishers' knowledge identifies environmental changes and fish abundance trends in impounded tropical rivers. Ecol. Appl. 23(2): 392-407. Wiley Online Library.

Hoenig, J.M. 1983. Empirical use of longevity data to estimate mortality rates. Fish. Bull 82(1): 898-903.

Holm, P. 2016. Fishers' information in governance-a matter of trust. Curr. Opin. Environ. Sustain. 18: 115-121. doi:10.1016/j.cosust.2015.12.005.

Johannes, R.E., Freeman, M.M.R., and Hamilton, R.J. 2000. Ignore fishers' knowledge and miss the boat. Fish Fish. 1(3): 257-271.

Kenchington, T. 2014. Natural mortality estimators for information-limited fisheries. Fish Fish. 15: 533-562.

Lima, E.G., Begossi, A., Hallwass, G., and Silvano, R.A.M. 2016. Fishers' knowledge indicates short-term temporal changes in the amount and composition of catches in the southwestern Atlantic. Mar. Policy $\mathbf{7 1}$ : 111-120. Elsevier.

Lorenzen, K. 1996. The relationship between body weight and natural mortality in juvenile and adult fish: a comparison of natural ecosystems and aquaculture. J. Fish Biol. 49(4): 627-642.

Mackinson, S. 2001. Integrating Local and Scientific Knowledge: An Example in Fisheries Science. Environ. Manage. 27(4): 533-545. doi:10.1007/s0026702366.

Maunder, M.N., Crone, P.R., Punt, A.E., Valero, J.L., and Semmens, B.X. 2017. Data conflict and weighting, likelihood functions and process error. Fish. Res. 192: 1-4. doi:http://dx.doi.org/10.1016/j.fishres.2017.03.006.

Neis, B., Schneider, D.C., Felt, L., Haedrich, R.L., Fischer, J., and Hutchings, J.A. 1999. Fisheries assessment: what can be learned from interviewing resource users? Can. J. Fish. Aquat. Sci. 56(10): 1949-1963. doi:10.1139/f99-115.

NOAA. 2007. Monkfish assessment summary for 2007. US Dep Commer, Northeast Fish Sci Cent Ref Doc. 0713.

Punt, A.E., Butterworth, D.S., de Moor, C.L., De Oliveira, J.A.A., and Haddon, M. 2014. Management strategy evaluation: best practices. Fish Fish. 17(2): 303-334. doi:10.1111/faf.12104.

Rademeyer, R.A., and Butterworth, D.S. 2015. Statistical Catch-At-Length assessment results for Sebastes mentella and S. fasciatus in Units 1 and 2. Cape Town. doi:http://www.mth.uct.ac.za/maram/pub/2015/CSAM Working Paper 2015_13.pdf.

Rochet, M.-J., and Rice, J.C. 2009. Simulation-based management strategy evaluation: ignorance disguised as mathematics? ICES J. Mar. Sci. J. du Cons. 66: 754-762. 
503 Sáenz--Arroyo, A., Roberts, C.M., Torre, J., and Cariño-Olvera, M. 2005. Using fishers' anecdotes, naturalists' 504 505 observations and grey literature to reassess marine species at risk: the case of the Gulf grouper in the Gulf

506 507

508 509 510

511 512

513 514

515

516

517

518

519

520

521

522 of California, Mexico. Fish Fish. 6(2): 121-133. Wiley Online Library.

Schnute, J.T, N.M Boers, R. Haigh, and Couture-Beil, A. 2015. PBSmapping, 2.69: user's guide. Canadian Technical Report of Fisheries and Aquatic Sciences. No 2549.

Silvano, R.A.M., and Valbo-Jørgensen, J. 2008. Beyond fishermen's tales: contributions of fishers' local ecological knowledge to fish ecology and fisheries management. Environ. Dev. Sustain. 10(5): 657. doi:10.1007/s10668-008-9149-0.

Sogard, S.M. 1997. Size-selective mortality in the juvenile stage of teleost fishes: a review. Bull. Mar. Sci. 60(3): 1129-1157.

Soto, C.G. 2006. Socio-cultural barriers to applying fishers' knowledge in fisheries management: an evaluation of literature cases. Simon Fraser University.

Stephenson, R.L., Paul, S., Pastoors, M.A., Kraan, M., Holm, P., Wiber, M., Mackinson, S., Dankel, D.J., Brooks, K., and Benson, A. 2016. Integrating fishers' knowledge research in science and management. ICES J. Mar. Sci. J. du Cons. 73(6): 1459-1465.

Valentin, A.E., Power, D., and Sévigny, J.-M. 2015. Understanding recruitment patterns of historically strong juvenile year classes in redfish (Sebastes spp.): the importance of species identity, population structure, and juvenile migration. Can. J. Fish. Aquat. Sci. 72(5): 774-784. NRC Research Press. doi:10.1139/cjfas2014-0149. 


\section{9. Figure captions}

524 Figure 1: a map of eastern Canada showing the main areas of fishing for redfish (Sebastes spp.) in Unit 1 (red)

525 and Unit 2 (green) and the home ports of fishermen who were interviewed for their knowledge of redfish fishing

526 operations and catches in the 1980s and 1990s. The Canadian provinces of Prince Edward Island (PEI),

527 Québec (QC), New Brunswick (NB), Newfoundland (NL) and Nova Scotia (NS) are shown. The inset map

528 situates the study area in North America. Produced using the R library PBSmapping (Schnute et al. 2015).

529 Figure 2: Natural mortality at age used in the two modelling approaches for Unit 1+2 redfish. An M level of 0.1

530 indicates that roughly $10 \%$ of the individuals in a population die each year due to natural causes such as

531 predation and disease.

532 Figure 3: estimates of the main survey (Unit 1 summer survey) biomass/abundance index for Sebastes mentella

533 in the two modelling approaches. Model estimates are lines while the data are points.

534 Figure 4: Fits of models (lines) to proportion at length data (points) from the main survey index for Sebastes

535 mentella in the interval $19-40 \mathrm{~cm}$ (regularly fished sizes). Model 2 values will vary slightly from the original graph

536 (Rademeyer and Butterworth 2015) as these values were digitized from paper and standardised to the 19-40 cm

537 length interval.

538 Figure 5: Model estimates of Sebastes mentella catch relative to official landings data (points) (a) and residuals

539 of predicted catch - reported landings (b).

540 Figure 6: Estimated biomass for the deepwater redfish (Sebastes mentella) Unit 1+2 stock resulting from two

541 different formulations of a statistical catch at length model.

542 Figure 7: Deepwater redfish (Sebastes mentella) catch in the Canadian Unit 1+2 stock in the official statistics

543 kept by Fisheries and Oceans Canada (black line) and an estimate of the minimum likely in the 1980s and early

544 1990s based on catch indicators compiled through interviews with redfish fishermen in this period (FKCE). 
Figure 1

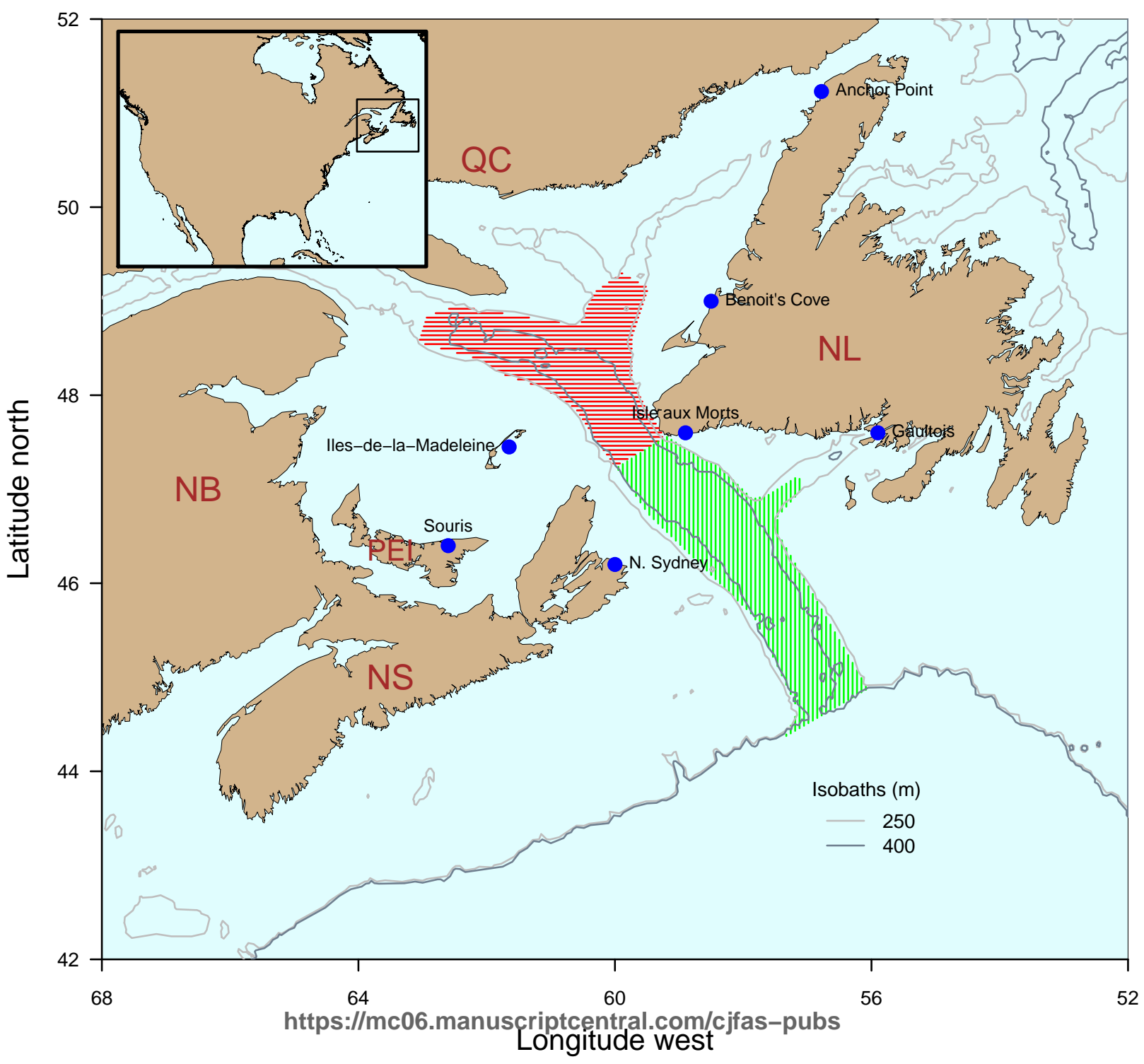




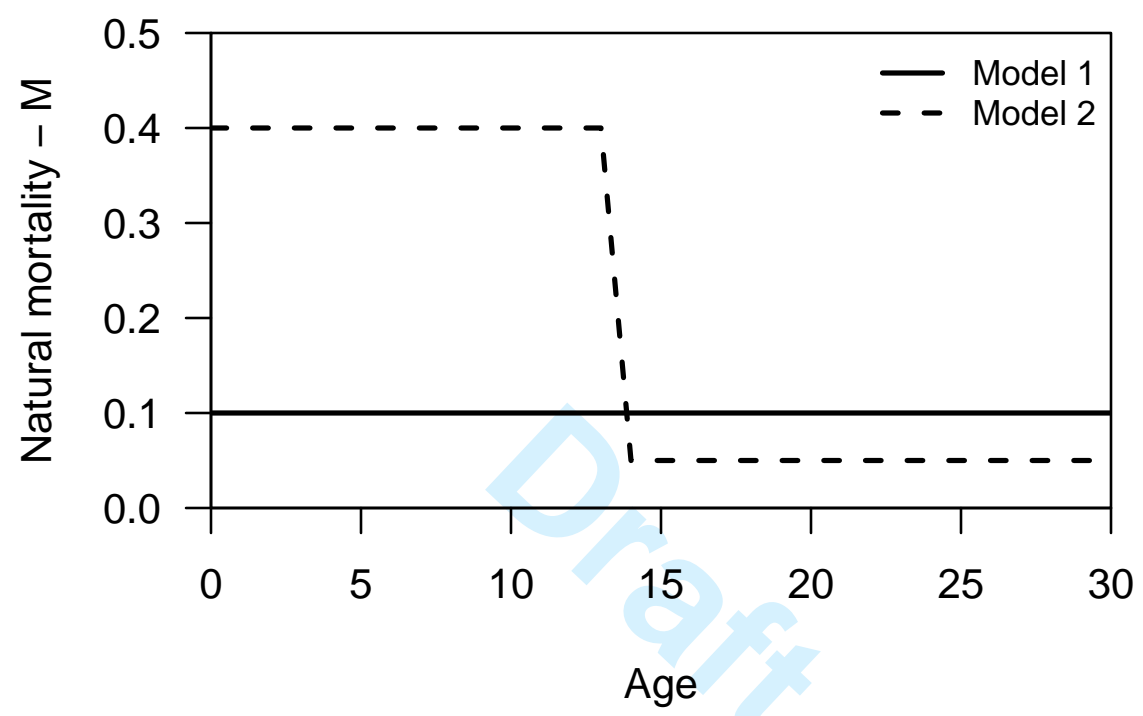

https://mc06.manuscriptcentral.com/cjfas-pubs 

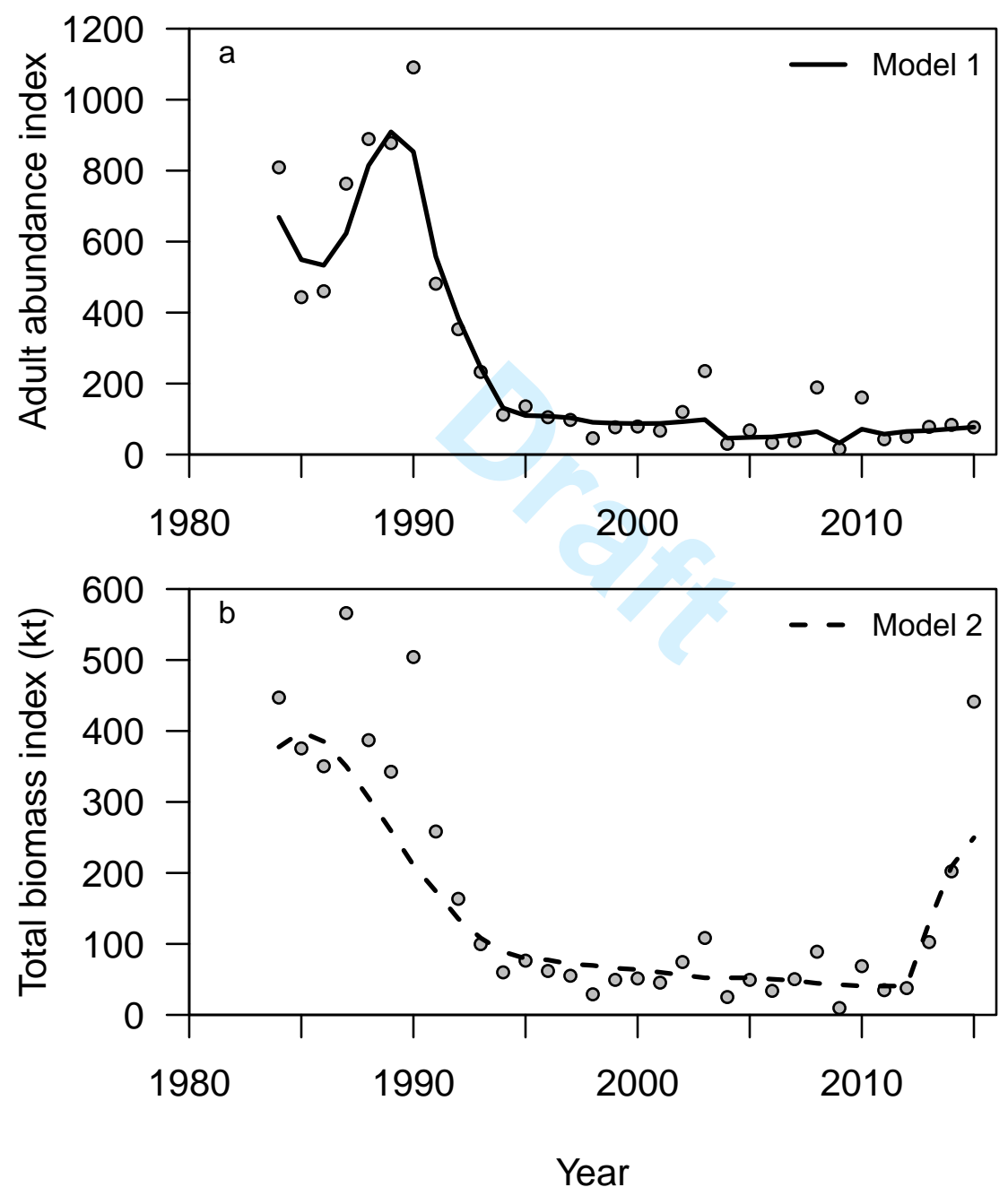

https://mc06.manuscriptcentral.com/cjfas-pubs 
Canadian Journal of Fisheries and Aquatic Sciences

Page 26 of 34

Figure 4

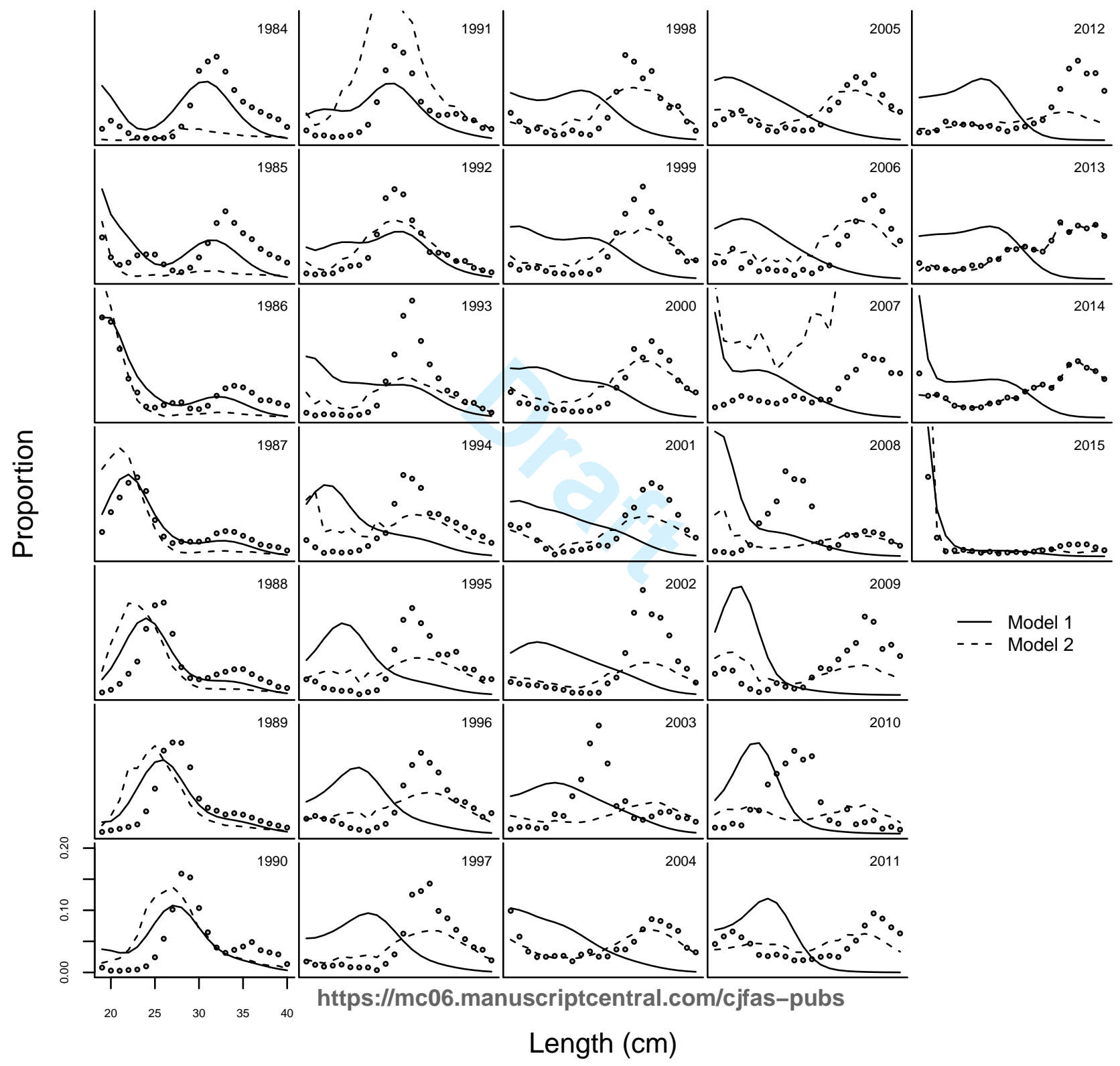



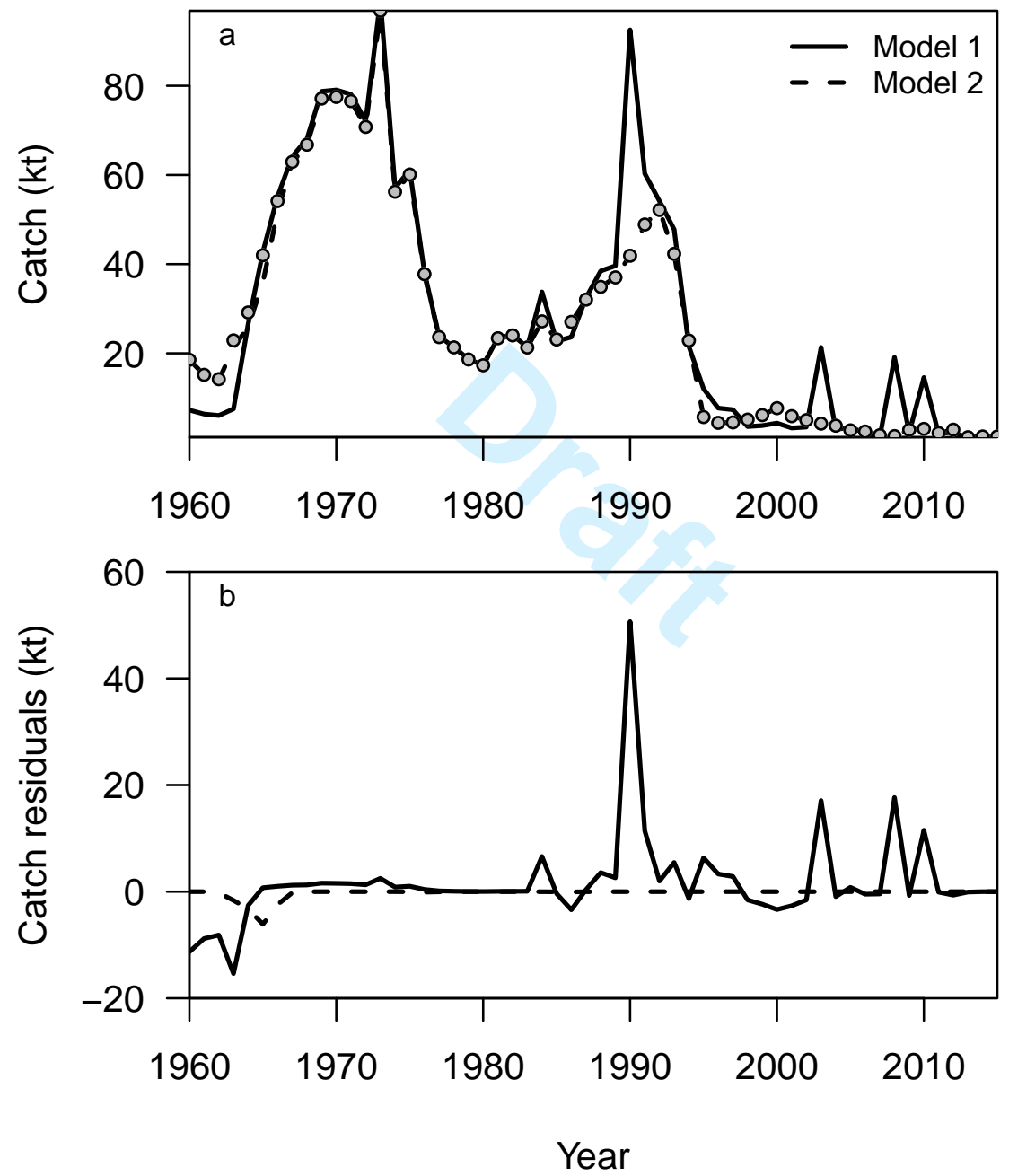

https://mc06.manuscriptcentral.com/cjfas-pubs 


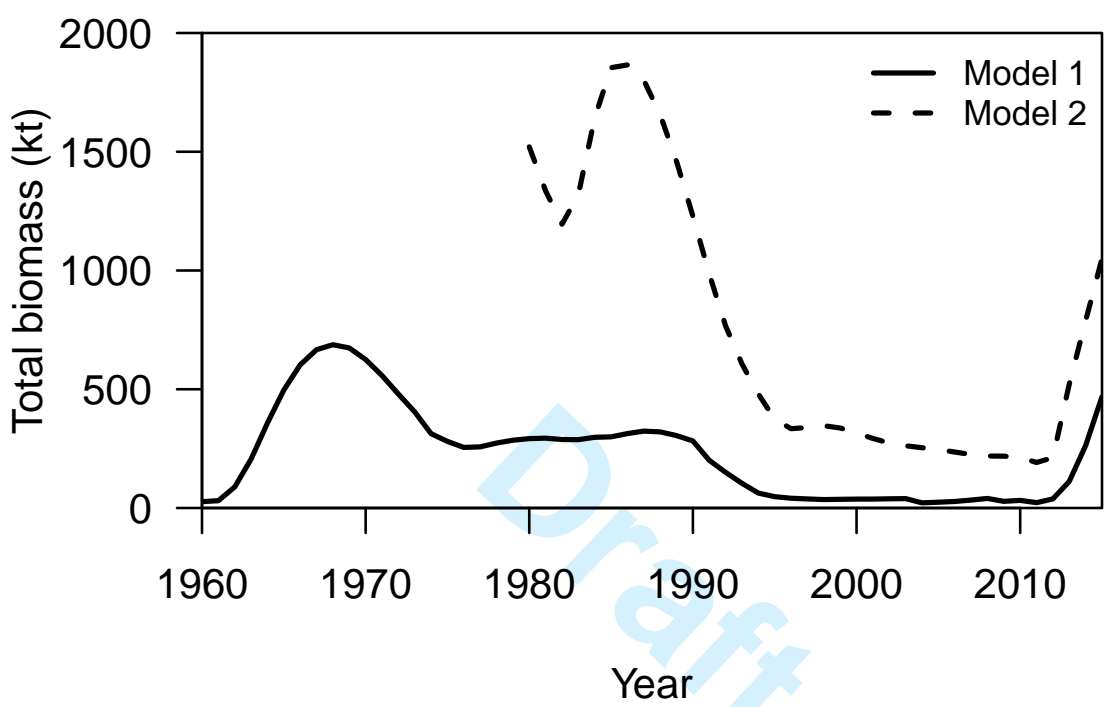

https://mc06.manuscriptcentral.com/cjfas-pubs 


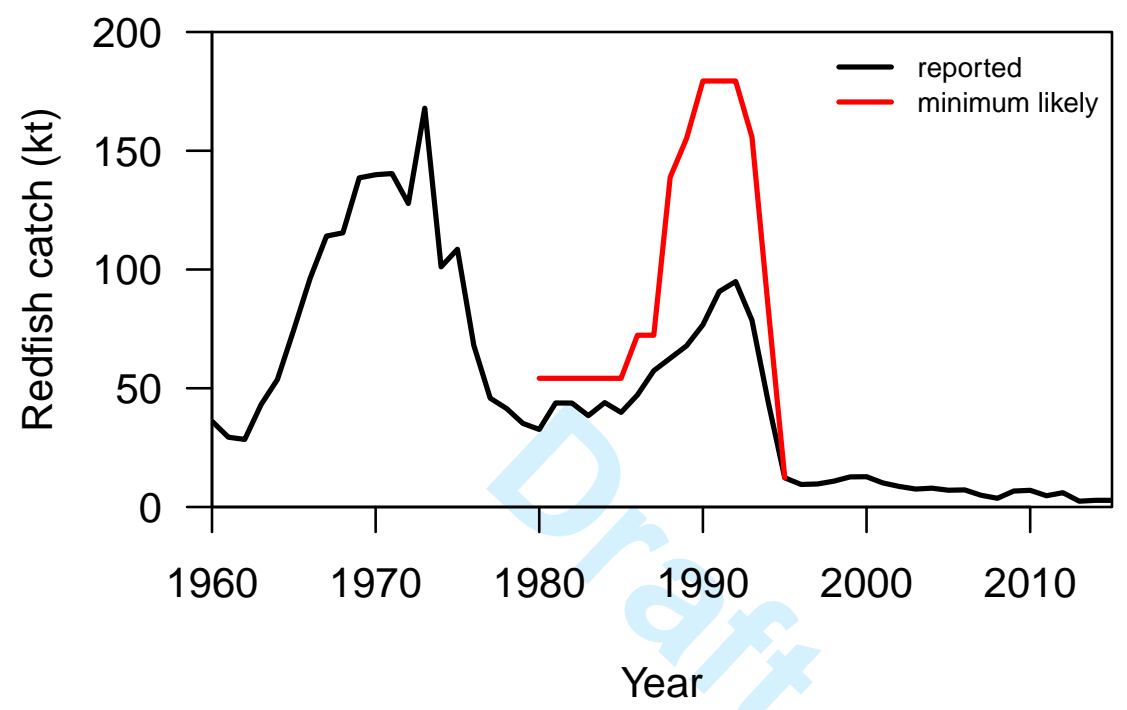

https://mc06.manuscriptcentral.com/cjfas-pubs 
Appendix A: Terms of Reference for the December 2015 framework peer reviewed

\author{
Assessment Framework for Unit 1+2 Deepwater (Sebastes mentella) and Acadian Redfish (Sebastes \\ fasciatus) and for Unit 3 Acadian Redfish
}

Zonal Peer Review - Quebec, Maritimes and Newfoundland and Labrador Regions

December 8-11, 2015

Mont-Joli (Québec)

Chairperson: Ghislain Chouinard

Part 1: Data Framework review in Unit 3 for Acadian Redfish (Sebastes fasciatus) - December 8, 2015

[removed for brevity]

Part 2: Assessment Framework for Unit 1+2 Deepwater (Sebastes mentella) and Acadian redfish (Sebastes fasciatus) - December 9-11, 2015

\title{
Context
}

Unit $1+2$ Redfish (Sebastes spp.) are distributed in the Gulf of St. Lawrence as well as the Laurentian Channel and Laurentian Fan areas off southern Newfoundland and Northeastern Nova Scotia. Both S. fasciatus and S. mentella in these areas are considered to be in a low relative biomass state and a 2012 peer review meeting showed them to be in the precautionary approach critical zone at $44 \%$ and $8 \%$ of their biomass limit reference points, respectively. These long lived species have proven difficult to age and age based modelling approaches have not as yet been applied successfully to either of these stocks. Reference point estimates from these stocks are the result of fitting a state-space Bayesian implementation of the Schafer surplus production model, BSP (McAllister \& Duplisea 2011, 2012). BSP does not make use of the length composition data available for these stocks and it was agreed at the 2012 reference point meeting that further approaches would be considered that could include these data in hopes of more accurately modelling population dynamics and improving management advice. Furthermore, both of these species display spasmodic recruitment characteristics and approaches which can more explicitly model recruitment should be advantageous. 
It has become apparent since the last evaluation in March 2012 (DFO 2012), that the 2011 and 2012 year classes of $S$. fasciatus and especially $S$. mentella are very strong and $S$. fasciatus in the south-eastern part of Unit 2 may be more closely related to Redfish in $3 \mathrm{LNO}$ than to Unit 1 and the western part of Unit 2. A new assessment should therefore consider how to both protect these year classes as pre-recruits, to avoid compromising yield per recruit potential by harvesting too heavily at relatively younger/smaller ages, and to enhance the level of the spawning stock biomass potential for the purpose of facilitating future recruitment prospects.

\section{Objectives}

Review of indices of abundance, fishery data and biological data for both species:

- Review indices of abundance in DFO research vessel surveys, industry surveys and commercial index fisheries

- Review fishery data inputs including spatial and temporal distribution, size composition

- Review comparative fishing experiments and conversion methods for GEAC-Teleost April 2015

Assessment of Model(s) to Monitor Stock Status and Productivity for both species:

- Review plausible method(s) to estimate the current status, specifically, stock size, size composition and fishing mortality, as the basis to provide advice to managers outlining their scope for use, strengths and weaknesses and how advice can be provided from these methods.

- Determine methodology to characterize stock productivity including reference points for fishing mortality and spawning stock biomass and past, current and projected states relative to these points for each species.

- Determine plausible forecasting method(s) for providing advice on a range of harvest levels associated with various fishing strategies including risk of being above or falling below biological reference points at different time frames (e.g. 5 years, 10 years, 25 years). Discuss the reliability of projections over different time periods.

- Discuss the potential and likely contribution of the 2011 and 2012 year classes to the fishery and to reproductive biomass over the cohorts' life spans and strategies for optimising their utilization and contribution towards future recruitment.

Minimal set of diagnostics, sensitivities and justifications expected from model fitting approaches: 
- Residuals from survey abundance

- Residuals from composition data

- Retrospective analysis going back at least 10 years

- Sensitivity to main productivity parameters of stock

- Sensitivity to data weighting assumptions

- Sensitivity to fishery and survey selectivity assumptions particularly the proportion of biomass generated from selectivity assumptions if selectivity is considered domed or non-sigmoidal

- For Bayesian assessments, sensitivity to bounds/priors including a clear statement when a posterior median parameter estimate is in improbable areas of the prior or at the bounds

- Justification for all parameters, especially model-scaling parameters (e.g. K and/or q) of model which strongly impact reference point estimates and sustainability of catch scenarios

- Selection of key run and justification. Any sensitivity runs identified as such with its particular purpose stated including a statement of plausibility relative to key run (quantitative or qualitative)

- Sensitivity to catch, especially in the early part of the time series where catches are less certain and likely underestimated

Establish a schedule for future processes and interim year advice:

- Establish a full assessment review period as well as interim-year advice utilizing the guidance provided by the March 2015 document from TESA

- Provide guidance on inter-framework review activities, including the procedure and frequency of providing fisheries management advice and events that would trigger an earlier-than-scheduled assessment

- Discuss data availability and resources required for dealing with potential stock structure issues that would be important for any future peer review process on stock structure

Establish requirements for model output for the assessment meeting in 2016. Minimally:

- $\quad$ Fittings expected

- Diagnostics expected

- Projections expected 
Other information relevant to the physical and ecological context of redfish in the Unit $1+2$ stock area

\section{Transparency}

In the interest enabling full evaluation and reproducibility of approaches explored as well as the longer term goal of continuity of the assessment methodology, contributors are expected to:

- make all data publically available in electronic format upon request

- provide a working document with publication expected as a CSAS research document

- make available all model code and inputs for the meeting and afterwards, upon request in electronic format and ideally should also be provided as a research document appendix. Reasonable conditions of use to protect intellectual property are acceptable as long as they do not compromise scrutiny of methods and/or continuity of the assessment of Unit $1+2$ redfish. Non-DFO model code can be provided on the condition that it not be circulated for purposes other than peer review and further assessment of this stock and will be utilized only for these stocks by meeting participants or their designates.

\section{Expected Publications}

- $\quad$ CSAS Proceeding

- CSAS Research Document(s)*

*Drafts of documents should be provided at least one week before the scheduled start of the meeting

\section{Participation}

- Fisheries and Oceans Canada (DFO) (Science and Ecosystems and Fisheries Management sectors)

- Aboriginal Communities/Organizations

- Provincial Representatives (NS, NB, NL, QC)

- Fishing Industry

- Non-governmental Organizations

- Academics and Other External Experts 


\section{References}

DFO. 2011. Recovery potential assessment of redfish (Sebastes fasciatus and S. mentella) in the northwest Atlantic. DFO Can. Sci. Advis. Sec., Sci. Advis. Rep. 2011/044. (Erratum: June 2013).

DFO. 2012. Reference points for redfish (Sebastes mentella and Sebastes fasciatus) in the northwest Atlantic. DFO Can. Sci. Advis. Sec. Sci. Advis. Rep. 2012/004. (Erratum: June 2013).

McAllister, M. and Duplisea, D.E. 2011. Production model fitting and projection for Atlantic redfish (Sebastes fasciatus and Sebastes mentella) to assess recovery potential and allowable harm. DFO Can. Sci. Advis. Sec. Res. Doc. 2011/057 vi +75 p.

McAllister, M. and Duplisea, D.E. 2012. Production model fitting and projection for Acadian redfish (Sebastes fasciatus) in Units 1 and 2. DFO Can. Sci. Advis. Sec. Res. Doc. 2012/103 iii + 34 p. 